\title{
Aproximación a un estudio sobre lo ornamental en la arquitectura de Melilla. El barrio del Real: un rjemplo de la impronta modernista
}

\section{Antonio Bravo Nieto}

Dibujos: Jesús M. Sáez Cazorla

He de comenzar estas notas con unos presupuestos básicos, que aportarán una mejor idea sobre su alcance, limitaciones y finalidad.

En primer lugar, el objeto central de este estudio, la ornamentación arquitectónica, presenta una doble vertiente: por un lado tenemos un conjunto de elementos, rasgos o tendencias, que situados en la ciudad de Melilla pertenecen a una o varias corrientes artisticas determinadas, y que como tales son o pueden ser objeto de estudio. Este es el concepto principal de estos apuntes.

Pero por otra parte, estos elementos conllevan un segundo enfoque relativo a su situación efectiva en la actualidad, a su conservación dentro del casco urbano de la ciudad.

La degradación de los adornos, y molduras en muchos casos es un hecho probado (anteriormente se han ido perdiendo mobiliario, interiores, etc.) lo que puede llevar en no mucho tiempo a su desaparición.

Es aqui donde surge un interrogante básico. ¿Existe la posibilidad de mantener o conservar todo el conjunto? La contestación entraña una compleja y entrelazada problemática de amplio espectro donde lo social y económico, lo estético y humano se funden en encontradas posturas.

Eludiendo estos aspectos conflictivos, hay que señalar, que en muchos casos, sobre todo en las casas pequeñas de los barrios, será la concienciación y sensibilización de propietarios e inquilinos de viviendas, lo que a la larga propicie el que se conserven o no, los elementos artísticos.

Todo aquello que facilite la comprensión o un mejor conocimiento del fenómeno modernista, ayuda a concienciar a las personas en cuyas manos está el cuidado directo de los edificios.

Citaremos inexcusablemente los trabajos de Constantino Domínguez Sánchez, los de Ana Riaño López y Laura Cantón Fernández, que han divulgado por todos 
los medios disponibles y contra viento y marea esta riqueza arquitectónica, asi como la labor de Luciano Tejedor Mata al respecto.

Hay que decir en este punto, que fuera de la discusión sobre el mayor o menor valor artístico, originalidad o importancia de la arquitectura de la ciudad, en ella debe recaer el interés de los propios melillenses si es que estos desean que Melilla mantenga esta imagen ornamental y modernista de principios de siglo.

El pasado es el producto de generaciones anteriores que nos legan su modo y condiciones de vida a través de ellas. Su destrucción supondría renunciar a una parte de nuestra historia.

Hay que considerar que es la citada imagen de conjunto lo que determina su mayor originalidad. No es la existencia de unos edificios de gran interés con fachadas, portales, escaleras, interiores, mobiliario, vidrieras, etc., lo que constituye la principal característica del modernismo en Melilla, sino la impronta particular que caracteriza a prácticamente todo el casco urbano con una serie de molduras decorativas en fachadas, lo que, por otra parte constituye la expresión y el lenguaje artístico de un arquitecto: Don Enrique Nieto y Nieto.

En otro sentido, la elección para este estudio del barrio del Real, es consecuencia directa de esta concepción.

.Así, en los quince sectores de la ciudad que tienen edificios y fachadas de algún interés, considero tres como núcleos principales, donde se encuentran las construcciones más características, seis de tipo medio alto y otros seis de tipo medio bajo.

El referido del Real, entraria dentro del grupo medio-alto, y el hecho de que no exista un número elevado de casas muy originales o destacables, no afecta metodológicamente al estudio, pues sí se da, en número que señalaré, una serie de molduras, enmarques y otros elementos decorativos, en numerosas edificaciones, que las dotan de una singular configuración.

El análisis y catalogación de este "lenguaje decorativo" puede resolver muchos interrogantes sobre la creatividad de Enrique Nieto, y al mismo tiempo determinar cuantitativamente su influencia en la ciudad de modo preciso, sin que este bajar al detalle, haga perder de vista que lo realmente original y loable sea el conjunto.

Antes de centrar el tema, es conveniente que comience con unas definiciones previas, que sitúen y enmarquen, en tiempo y estilo, el modernismo en Melilla.

Así, se destaca esta corriente como un fenómeno heterogéneo, con múltiples ramificaciones y su posible unidad en algunos aspectos.

Señalar las variadas tendencias modernistas, resaltando el estilo Sezession, por su influencia en la ciudad, y ver someramente las corrientes de este movimiento en Cataluña y su diversidad, destacando la que vendría a Melilla en 1909.

También hay que primar la decoración, presentando sus fuentes y raices, y por último, cómo se plasmarian todos estos elementos de la mano de Enrique Nieto en una ciudad por hacer.

No es este acercamiento, un intento de abarcar todo el fenómeno modernista, pues como puede verse con claridad se han excluido, absolutamente, parcelas importantes, para subrayar aspectos que, creo, pueden tener incidencia en la finali- 
dad de estas notas. No pueden servir pues, como resumen del fenómeno modernista a nivel general, ya que no es ese su objetivo.

\section{La heterogeneidad de lo modernista}

Primeramente habria que definir, si es que esto es posible, al término modernismo. Encontraremos muchas dificultades en esta tarea, pues el concepto variará ade unos países a otros, e incluso los críticos de un mismo pais presentarán una dimensión u otra del mismo.

Así, "en un principio, el modernismo designó un movimiento de amplitud cultural y sociológica, luego fue un estilo y finalmente acabó siendo una moda" (1).

Esta corriente plasmó en una renovación estructural y decorativa con ramificaciones en las artes menores y aplicadas, joyería, mobiliario, escultura, cerámica, vidrieras, grabado, carteles, etc..., aunque las más importantes representaciones serían las arquitectónicas.

Sus formas no son siempre fáciles de definir, y sus fronteras carecen de una línea precisa. Por esto, Bernard Champigneulle estima que es "imposible fijar los elementos de un estilo modernista y asignar a este fronteras morfológicas" pues, ¿cuál sería el elemento definidor y característico de este movimiento?, ¿la espiral, la curva? Pero entonces ¿dónde colocamos el estilo de Mackintosh o a Van de Velde y los vieneses? (2).

No se puede agrupar bajo un mismo nombre tendencias cuyo lenguaje varía entre sí tan drásticamente.

Para Carlos Flores, la diversidad de corrientes hacen del modernismo lo más opuesto a una doctrina unitaria, pura, y ortodoxa, dando cabida en su seno a factores de muy diverso signo y a productos que merecen valoraciones cualitativas muy dispares (3).

¿Cómo definir entonces el modernismo? No debemos limitarnos a criterios basados en apariencias y reglas exclusivamente visuales, este, responde ante todo, a una actividad anímica, (4), un deseo común de ruptura, libertad, juventud y novedad capaz de imprimir a la arquitectura de un tiempo nuevo un carácter nuevo (5).

Será la postura revolucionaria ante el eclecticismo clasicista, que busca un nuevo lenguaje arquitectónico con nuevas formas tendentes a un mayor expresionismo y vitalidad, lo que la dota de cierta unidad.

(1) PASTOR PEREZ, Francisca, "Arquitectura modernista en Málaga”, Revista Jábega, Diputación Provincial de Málaga, 2. trimestre 1979, pág. 369.

(2) CHAMPIGNEULLE, Bernard, Enciclopedia del modernismo, Barcelona, Poligrafa, 1983, pảg. 94-95.

(3) FLORES LOPEZ, Carlos, "Notas" en Leonardo Benévolo, $H .^{a}$ de la arquitectura moderna, Barcelona, Gustavo Gili, 1979, pág. 358.

(4) CHAMPIGNEULLE, Bernard, obra citada, pág. 100.

(5) FLORES LOPEZ, Carlos, obra citada, pág. 361. 
La búsqueda de la modernidad "debe situarse como dato significativo por encima de cualquier repertorio formal" (6), los creadores pretenden "romper amarras con el pasado, alumbrando formas artisticas que emplearán técnicas y materiales nuevos" (7). El estilo resultante será por esto, original.

Pero los modernistas, consciente o inconscientemente, utilizaron viejos elementos que integrarian en sus obras.

Podemos finalizar estả cuestión, como señala Carlos Flores, dando una definición de tipo amplio para estos artistas, "como participes de unos ideales comunes, expresados en lenguajes distintos" (8).

\section{Tendencias y evolución. La corriente novecentista}

Existen dos corrientes principales en el estilo modernista, "la orgánica y la geométrica", "una caracterizada por las formas concavo-convexas (Horta, Van de Velde, Gaudi) y otra apoyada fundamentalmente en un rigor geométrico (Wagner, Mackintosh)" (9).

Hemos visto ya, lo heterogéneo de este fenómeno. No es mi intención analizar las diversas corrientes del estilo en los diferentes países; incidiré aquí en el Sezessionismo vienés, por la influencia que posteriormente tendrá en la evolución de la arquitectura melillense.

Alejado de otra tendencia modernista, el Art Nouveau, de caligrafía sinuosa y ondulante, en el estilo Sezessión, según palabras de su principal mentor, Otto Wagner, "la lógica constructiva debe presidir la composición arquitectónica". La decoración se traduce en un simbolismo, pues la ornamentación aparece en las partes de los edificios que no interfieren negativamente las lineas de la arquitectura (10).

La Sezession vienesa ofrece ya el germen de una estética, la del Art Deco. Por esto, más tarde, los mismos arquitectos reaccionarán contra el modernismo, adoptando los volúmenes y superficies desnudas, exponentes de la arquitectura racional.

Champigneulle cree que este estilo fue una primera etapa hacia el alcance de la pureza formal racionalista (11).

Es esta evolución es donde hay que encuadrar la corriente novecentista, caracterizada en la "búsqueda de un depurado lenguaje estructural y un nítido perfil de

(6) FLORES LOPEZ, Carlos, Ibidem, pág. 361.

(7) CHAMPIGNEULLE, Bernard, obra citada, pág. 29.

(8) FLORES LOPEZ, Carlos, Gaudi, Jujol y el modernismo catalán, Madrid, Aguilar, 1982, pág. 124.

(9) FUSCO, Renato de, Historia de la arquitectura contemporánea, Madrid, Hermán Blume, 1981, I, págs. 107 y 110.

(10) CHAMPIGNEULLE, Bernard, obra citada, pág. 137.

(11) CHAMPIGNEULLE, Bernard, Ibidem, pág. 135. 
formas más reposadas y suavemente depuradas" (12).

Esto se realizará con la recuperación de un léxico clasicista y una referencia permanente con la recuperación de un léxico clasicista y una referencia permanente a las culturas mediterráneas.

La "ruptura con el Modernismo y la intolerancia con actitudes vanguardistas forman parte de los limites que el Novecentismo se traza" (13).

\section{Desarrollo y evolución del Modernismo en Cataluña}

La arquitectura melillense tiene sus raices más directas en el movimiento modernista catalán, es básico pues, ofrecer una visión general de este. El modernismo catalán "debería ser considerado como un fenómeno de muy amplio espectro... alejado de cualquier puritanismo u ortodoxia, y dentro del cual, como en un inmenso saco sin fondo, tendrian cabida las más diversas y en ocasiones incluso contradictorias tendencias".

Carlos Flores ha sistematizado las corrientes que se dan en la región catalana. Asi señala un modernismo en torno al fenómeno de la Renaixença, otro formado por los continuadores de Gaudi y un tercero llamado Manierista o ecléctico (14).

Veamos sucintamente estos movimientos.

La Renaixença constituye la más genuina expresión del movimiento cultural catalán que a caballo de los dos siglos produce obras de notable interés.

Su campo de acción es muy amplio, desde la política hasta la arquitectura; en ésta se busca lo historicista, lo medieval, para reelaborar y transformar en novedoso y original estos elementos.

Por otro lado en torno a la figura de Gaudí se constituye un grupo de colaboradores y seguidores, que pretenden con mayor o menor acierto continuar la línea del maestro constituyendo lo que se ha denominado gaudinismo.

En tercer lugar, se desarrolla el movimiento manierista o ecléctico. Me centraré en este, pues será el que con el arquitecto catalán Enrique Nieto, arribe a Melilla en 1909. Sus rasgos son por tanto imprescindibles para iniciar cualquier acercamiento a la arquitectura de esta ciudad.

Los eclécticos presentan influencias procedentes de los correspondientes movimientos europeos. "La propagación de las corrientes modernistas, supondría casi siempre un nuevo eclecticismo basado en repertorios formales de última hora, en la mayor de los casos las novedades se acusarán especialmente en las fachadas, a lo más alcanzarán a portales y escaleras sin llegar a suponer por lo general transformaciones arquitectónicas más profundas." (15) Veremos como Enrique Nieto va más lejos de este planteamiento.

(12) SOLA MORALES RUBIO, Ignacio de, Eclecticismo y vanguardia. El caso de la arquitectura moderna en Cataluña, Barcelona, Gustavo Gili, 1980, pág. 74.

(13) SOLA MORALES RUBIO, Ignacio de, obra citada, págs. 73 a 88.

(14) FLORES LOPEZ, Carlos, Gaudi, Jujol y el modernismo catalán, pág. 57.

(15) FLORES LOPEZ, Carlos, Ibidem, pág. 105. 
Como ha señalado José M. ${ }^{a}$ de Azcárate, la última fase en la evolución del modernismo refleja la influencia del sezessionismo vienés, de Otto Wagner y J. M. Olbrich, (16). Serán sobre todo los esquemas del primero los que asimilaría la corriente manierista.

Ignacio de Solá, destaca en las corrientes postmodernistas (junto a las derivaciones gaudinistas y la evolución de la sezessionstil) sendas tendencias, popularismo y monumentalismo, este último a la búsqueda del lenguaje clásico frente a lo modernista (17).

Estas corrientes serán las que se integren en esa tendencia heterogénea que se ha venido llamando novecentismo y de la que tan buenos ejemplos posee Melilla.

Podemos concluir de forma general, diciendo que junto a las obras de puro mimetismo, habria que incluir aportaciones personales de notable interés. En este sentido hay que entender la del arquitecto Enrique Nieto y Nieto tanto por lo prolifico y variado de su creación, como por haber dotado a Melilla de una impronta modernista de amplio espectro, que hay que valorar en su conjunto.

\section{Decoración}

Señalábamos ya la importancia que la decoración y lo ornamental presenta en el modernismo, y que en su vertiente arquitectónica va a ser la principal característica de la ciudad de Melilla.

La fuente de inspiración principal es la naturaleza, donde la asimetría está a sus anchas. Esta, será analizada en detalle y sometida a una catarsis decorativa a la búsqueda de su sintesis.

Se eligen elementos figurativos que se prestan dócilmente a las elegantes flexiones curvilíneas: cintas, tallos florales, cisnes, pavos reales y otras aves, largas cabelleras femeninas, etc., repertorio que encierra connotaciones iconográficas de orden simbolista y literario. El rasgo más típico es la linea ondulante y asimétrica que forma a menudo motivos ornamentales complejos.

En el desarrollo histórico del Art. Nouveau el elemento decorativo va perdiendo cada vez más su carácter de añadido al esquema funcional o instrumental del objeto, para tender a conformar a éste como ornamento y transformándose así de superestructura en estructura (18). Se eleva pues la decoración a un puesto principal y determinante en la creación arquitectónica.

Veamos una serie de obras literarias y artísticas, que determinaron en gran modo la elección de lo vegetal en la estética modernista, y crearon el clima apropiado para la expansión de todos estos elementos decorativos.

(16) AZCÁRATE, José M." de, Panorama del arte español s. XX, Madrid, UNED, Aula Abierta, 1978, pág. 38.

(17) SOLA MORALES RUBIO, Ignacio de, obra citada, pág8. 73 a 88.

(18) CARLO ARGAN, Giulio, El arte moderno 1770-1970, Valencia, Fernando Torres ed., 1975, pág. 246. 
Cristopher Dresser en Antologia de ornamentos (1856) proclama la estilización de los vegetales, "la flor estilizada es ahora motivo predilecto, el artista moviéndose en un marco bien definido echa mano del árbol y su follaje, de la planta $y$ sus flores, para modificarlos, triturarlos $y$ someterlos a sus exigencias" (19).

Otro ejemplo destacable tenemos en Eugene Grasset, en su obra "La Planta y sus aplicaciones ornamentales", de 1896.

Son interesantes las teorias de Owen Jones, en su "Gramática del Ornamento" de donde se extrae que este "debe basarse en una construcción geométrica" (20). La línea elegida será la curva, pero traduciendo, no la apariencia sino su estructura geométrica, idea que influirá a Morris.

Y en consonancia estilistica, se pasa de las curvas vegetales a la curva femenina, llena de sensualidad y belleza. La mujer pasa a ocupar un lugar central en la decoración modernista y en las representaciones escénicas.

Para Cataluña serán Alphons Mucha, junto con los pintores prerrafaelistas y arquitectos como Olbrich y Mackintosh, los responsables de la introducción del floralismo, rasgo esencial del lenguaje de todo el modernismo catalán (21).

De este sustrato beberán toda una serie de arquitectos, entre los que se encontraba Enrique Nieto.

\section{Enrique Nieto y su influencia en Melilla}

En 1909 llega desde Barcelona el arquitecto don Enrique Nieto y Nieto a Melilla (22), y con él, trae el germen de lo que será posteriormente el estilo de toda una ciudad.

Ya se han expuesto cuales eran las tres tendencias en Cataluña, y el ambiente de riqueza creativa que distinguía esta región del resto peninsular.

Veamos ahora de qué corriente estética participará Nieto, y cual será su solución a lo heterogénero del estilo modernista.

Pese a haber colaborado en los trabajos de la Casa Milá, y el hecho real de que conoció la obra de Gaudí, no puede afirmarse, frente a lo que se ha venido diciendo, que sea un seguidor del maestro de Reus, ya que ni en las soluciones estructurales, ni en las plantas, presenta ninguna semejanza.

(19) CAMPIGNEULLE, Bernard, obra citada, págs. 87-89.

(20) CAMPIGNEULLE, Bernard, Ibidem, pág. 44.

(21) FLORES LOPEZ, Carlos, Gaudi Jujol y el modernismo catalán, pág. 68.

(22) Datos biográficos sobre Enrique Nieto podemos encontrar en: TARRAGO CID, Salvador, "Don Enrique Nieto y Nieto", Memoria de la Cátedrs Gaudí curso 1968-69, Barcelona, Gea, 1970.

SARO GANDARILLAS, Francisco, "Algo sobre Enrique Nieto", ponencia en la "Semana sobre el modernismo" en Melilla, 20-3-85.

El profesor Juan Bassegoda Nonell y Francisco Mir Berlanga han aportado datos sobre este arquitecto en la "Semana sobre el modernismo" en Melilla, dias 20-21-22 de marzo de 1985. 
No existe en Melilla ningún edificio con características "gaudianas", o que pretenda copiar, continuar, repetir, o recrear sus rasgos.

Otra corriente es la constituida por la Renaixença, que debemos circunscribir únicamente al área catalana, aunque algunas de sus características, como la reelaboración de un lenguaje artístico extraido del pasado histórico, aflore en ocasiones de la mano de Enrique Nieto.

Como ya apuntábamos, será la corriente manierista (23), la que de una u otra forma se desarrolle en la ciudad de Melilla.

Veiamos algunos de sus rasgos principales, señalaremos ahora que este arquitecto, utilizará un lenguaje heterogéneo, donde se darán cita varias y variadas fuerzas estilísticas, por un lado la influencia del Art Nouveau, por otro la del Sezessionstil vienés, hacen que lo ondulante o sinuoso, y lo geométrico y lineal afloren en uno $u$ otro edificio, $o$ incluso en el mismo.

Esta concepción determinará por un lado, que en muchos casos lo modernista se acuse principalmente en las fachadas, portales y escaleras, por otro, que las plantas de los edificios muestren lo convencional de su estructura (24).

No obstante el desarrollo de este movimiento es mucho más rico y variado, ya que se trató de una corriente de amplio espectro, con un sólido apoyo social en la burguesia.

Asi sus modulaciones aparecerán en los interiores, en diferentes artes como rejería, vidrieras, mobiliario, pinturas, configurando locales comerciales, etc... (25).

Todo intento de poner encorsetadas etiquetas puede desdibujar el objeto que quiere ser definido. El intentarlo con la obra de Enrique Nieto reviste aún más dificultades si cabe.

Su proceso evolutivo lleva hacia una enorme mixtificación estilística. La mezcla hace dificil una comprensión de todo el proceso sufrido por este arquitecto (26), que no se quedará estancado en ningún estilo.

Parte de los presupuestos que fundamentaban su ráz ecléctica le conducirán hacia una reacción contra las ondulaciones vegetales modernistas. La influencia de la Sezessión irá cambiando muy gradualmente su estilo que se descargará de decoración al buscar la belleza de lo lineal, de las estructuras geométricas, a la vez que se recrean nuevos elementos del lenguaje clásico de corte mediterráneo. Es así como aparece su etapa novecentista, con grandes y muy notables edificios.

(23) Prefiero utilizar esta denominación, siguiendo a Carlos Flores, frente a la de ecléctica, por las connotaciones desvalorativas de esta última, y por la confusión a que puede llevar con la corriente ecléctica de corte historicista.

(24) El profesor Juan Bassegoda Nonell, en conferencia pronunciada sobre arquitectura modernista fuera de Cataluña, señalaba una caracteristica y original disposición de los empujes y sustentos a base de pilares de hierro colado en algunos edificios de Enrique Nieto, abriendo un campo inédito y de enorme interés para la investigación de su obra. "Semana sobre el modernismo" en Melilla, 22 de marzo de 1985.

(25) CANTON FERNANDEZ, Laura y RIAÑO LOPEZ, Ana, "El ámbito modernista de Melilla", Aldaba núm. 3, 1984, págs. 20-23, se ofrece una exposición de estas artes en Melilla.

(26) TARRAGO CID, Salvador, artículo citado, pág. 30. 
Evolución paralela presentan los portales, donde la puerta principal de entrada, asi como la decoración vegetal, va cediendo paso a otro tipo que se inscribe totalmente en la corriente Art Deco.

Una última etapa llega cuando va desapareciendo totalmente la ornamentación en relieve. Con el racionalismo prima lo volumétrico, los espacios se crean con grandes y cerradas balconadas curvas, que por otra parte nunca abandonarán una decoración de corte novecentista, muy geométrica y estilizada de guirnaldas y vegetales en esgrafiados. Son casas muy características, con estucos en rojo o rosa oscuro, y mucho menos abundante en verde o azul.

Pero a pesar de esta heterogeneidad, se advierte un quehacer propio y caracteristico, que huye tanto de lo discordante como de la exageración, lo que crea una conseguida línea de mesura y moderación en todas sus obras a modo de sello personal o impronta que encontramos en toda la ciudad.

Ya situada la obra en unas coordenadas precisas, ha llegado el momento de preguntarse si la creación de Enrique Nieto es original, o si aporta algo en concreto a la ciudad de Melilla.

En todo caso las respuestas no son simples. Señalaré algunos datos que puedan esclarecer la cuestión.

Un aspecto de este arquitecto ha sido descrito por Salvador Tarragó Cid como "querer elevar la mediocridad compositiva y el mal gusto, a la categoria de obra artística", opina que "su obra registra este intento difícil de hacer construible, es decir arquitectónico, lo heterogéneo, lo ambiguo, el mal gusto, la cursilería, o la urbanidad encorsetada" (27).

Señala a su vez que es en este sentido como podría compararse sus circunstancias con la problemática gaudiana. Entre la contradicción del artista, del libre quehacer y de las circunstancias y el público burgués a los que debe ceñir su producción, serpentea su obra creativa. El arquitecto se convierte en un creador total, "bajo la ideología del trabajo compartido y de la obra bien hecha, aparece en la realidad el principio de una subdivisión social del trabajo, estructurado desde arriba, piramidalmente" (28).

Por esto, lo más importante, a la vez que la creación de "un molduraje y de cuantos elementos decorativos se precisasen para la realización de aquellos estilos" es la "formación de una escuela local de artesanos (yeseros, decoradores, constructores, etc...) a los que inspiró completamente y que de hecho repitieron hasta el infinito... su vocabulario artístico" (29).

Por este medio, su influencia llegó a otros arquitectos e ingenieros militares que en aquella época trabajaban en Melilla.

En este punto hay (jue decir que me parece exagerada la atribución que se ha hecho a Nieto de realizar directamente 4.000 proyectos. En todo caso se ocuparía de su supervisión.

(27) TARRAGO CID, Salvador, Ibidem, pág. 33.

(28) COMBALIA, Victoria, "Vidrieras modernistas", El País, 12 de mayo de 1984.

(29) TARRAGO CID, Salvador, artículo citado, pág. 28. 
Las escuelas locales de artesanos, con su hacer diario, se aplicaban a todo tipo de edificios que se construian y no únicamente a los del arquitecto que nos ocupa.

Así trabajaban también para los otros técnicos que hemos citado, e incluso, como es el caso de los barrios, fuera del centro, sobre casas que habian sido construidas por maestros de obras o por simples albañiles.

Por esto, en toda la ciudad aparecen molduras, marcos, balaustradas, etc., que obedecen al referido lenguaje artístico.

El hecho de que aparezcan elementos decorativos creados por Nieto en unos edificios, no significa explícitamente que hayan sido construidos por él.

A Enrique Nieto le cupo la creación del lenguaje, y este fue luego empleado por otros, de aquí uno de los rasgos de su originalidad.

Este fenómeno lo veremos reflejado entre otros muchos en el Barrio del Real. Conforme se van construyendo las casas, en su mayor parte bajas, o cuando estas se amplían o mejoran, paralelamente se les empiezan a aplicar todo tipo de molduras en las fachadas, ya sean modernistas o de otros estilos, y esto es, lo que hoy día configura a toda la ciudad con ese sello tan personal.

De lo dicho se desprende que el modernismo se hace, en esta faceta determinada, popular, al ser un elemento utilizado por las clases obreras para ornamentar sus viviendas. También, y en este caso, su cronología es muy tardía con respecto a otras zonas, pues se seguirán aplicando mucho después que el fenómeno modernista desapareciera como tal, $e$ independientemente de que Nieto vaya variando su estilo en las casas que construia personalmente, en sus grandes obras.

Por todo esto, lo más importante, será la impronta que a causa de su expresión decorativa, extenderá a toda la ciudad. Asi "Melilla hay que valorarla en su conjunto "como" exponente de un complejo cultural único" (30).

\section{Barrio Real}

A partir del tratado hispano-marroqui de 1860 , Melilla tenía la posibilidad de expandirse, desde el núcleo antiguo de la ciudad, hacia los llanos circundantes.

Pero las acciones de guerraa determinaron las condiciones de este crecimiento. Será la campaña de 1909, la que propiciará la creación de los barrios del Hipódromo y del general Real, y de que se constituyan en barrios populosos, de artesanos y obreros.

Será pues a partir de 1910 , cuando de modo expontáneo y con una rapidez inusitada surjan estos barrios, veamos muy sucintamente su conformación.

Su trazado, como el de toda la ciudad de Melilla, será realizado por la Comandancia de Ingenieros. Sus calles son amplias, alineadas a cordel y en cuadrículo,

(30) TEJEDOR MATA, Luciano, "Aproximación a la arquitectura melillense", El Telegrama de Melilla, 20, julio, 1982. 
siendo sus solares de $100 \mathrm{~m}^{2}$, presentando a la calle $10 \mathrm{~m}$. ó 20 si hace esquina.

En 1914, contará con 836 casas (la ciudad tiene por entonces 3.046) y su población es de 5.407 personas (31).

Para 1927-30, las viviendas serán 758, repartidas en 676 de planta baja, 66 de bajo y un piso, 15 de tres pisos y una de cuatro. La disminución respecto a 1914 puede deberse a una reagrupación de casas o a derribo de barracas insalubres (32).

Y más o menos permanecerá de esta forma hasta hoy, construyéndose alguna manzana a la izquierda de la calle Mar Chica a partir de 1934, y en algunos casos elevándose la altura de los edificios.

A partir de 1930, se puede decir que la construcción estaba paralizada pues comienza una época de crisis profunda, destacando los pocos edificios construidos en estas fechas sobre los demás por su estilo peculiar.

Hay referencia de que trabajaron en esta zona, los siguientes técnicos: ingenieros Tomás Moreno y Rodrigo González, arquitectos Mauricio Jalvo, Francisco Hernánz y Eduardo Caballero; en fechas y estilos diversos.

Vemos como Enrique Nieto no realizó todos los edificios del barrio, es más, muchos de estos, inicialmente fueron barracas o casas de mamposteria construidas por albañiles. Su mejora, o cuando se ampliaban y aumentaban en altura, suponía el añadido de un rico molduraje decorativo en las fachadas. Melilla.

Incidamos ahora en un rasgo que ya se ha apuntado sobre el modernismo en

Para Bernard Campigneulle, la pretendida alianza entre estética y sociedad fracasó, pues "no sólo fue rechazada por las clases modestas, sino que ni siquiera llegó a influir en el gusto popular" (33).

Esta caracteristica es sólo relativa en lo que respecta a la ciudad de Melilla, pues aqui sí hubo influencia modernista en el gusto del pueblo, como consecuencia de la labor de los talleres de yeseros. La ornamentación fue un elemento en el gusto de todos, y no sólo de la clase social que crea las condiciones adecuadas para que este movimiento aparezca: la burguesía.

Sólo esta expansión en lo popular ha podido legarnos una cantidad de obras tan elevada en todos los lugares de la ciudad.

Centrándonos en el Barrio del Real, hay que decir que la mayor parte de ellos están compuestos por una planta baja. La ornamentación se distribuye en la fachada y en menor grado en los interiores.

Las primeras aparecen configuradas por una serie de molduras que se aplican a las paredes, veamos los elementos más característicos de esta decoración.

La fachada se corona con una blaustrada que sirve de antepecho a la azotea,

(31) Junta de Arbitrios de Melilla, Memoria explicativa de su gestión 1914, Melilla, Imprenta Telegrama del Rif, 1915, pág. 37.

(32) Junta Municipal de Melila, Memoria de su actuación 1927-30, Melilla, Imprenta Telegrama del Rif, 1931, pág. 258.

(33) CHAMPIGNEULLE, Bernard, obra citada, pág. 130. 
ésta puede ser de varios tipos, asi aparece la más corriente a modo de balaustre, y otros más interesantes de círculos con vegetales o entrelazados diversos.

Inmediatamente debajo está la cornisa, moldura cóncava o convexa que como friso, recorre horizontalmente la parte superior de la fachada.

Puede estar decorada, bien con hojas de acanto o flores como la rosa, bien con figuras geométricas o cuerdas anudadas de simbologia franciscana.

Los vanos se enmarcan con molduras muy variadas tanto geométricas o lineales, como vegetales con ondulaciones.

En otros casos pueden aparecer guirnaldas de flores, o bandas decorativas a lo largo de toda la fachada, o bien un típico almohadillado.

Por desgracia los materiales empleados para las molduras no son nobles y la degradación afecta en gran modo a estos elementos.

Así hay que señalar como más perecederos, las balaustradas, que compuestas en algunos casos por una estructura interna de hierro, lo que en un principio la sustentaba, hoy día la revienta al oxidarse este. En tres años se han perdido 8 balaustradas.

También fueron desapareciendo molduras, conforme se aumentaban en altura los edificios, o cuando los talleres desaparecieron y no era posible reponerias.

Las cornisas se mantienen en gran parte, y en un término medio de conservacion podríamos considerar los enmarques de vanos, pues en muchos casos la atención y cuidado de los propietarios hacen que estos aparezcan hoy día en un estado perfecto, mostrando toda su belleza, ejemplo que por desgracia no es seguido por todos, como lo demuestra la cifra de 21 enmarques que se han perdido desde junio de 1981 hasta la actualidad.

Otros elementos embellecen estas casas. Así en puertas, barandillas y rejas de balcones, es muy corriente el hierro forjado, unas veces de tipo simple otras con ondulaciones.

También puede aparecer con cerámica vidriada de vistoso colorido, que hace resaltar aún más, cualquier ornamentación, como en el caso de Cataluña 14.

Las casas de dos plantas o más, presentan una disposición parecida, pero los enmarques pueden variar de un piso a otro, y aparecen elementos decorativos en los portales.

La proporción de casas con piso respecto a las que no lo tienen es de un $20 \%$ dentro de los edificios que presentan algún interés.

Veamos en este barrio concreto, ejemplos singulares que muestren como se va plasmando la evolución en los estilos que imperan en toda la ciudad.

Tal vez la casa más modernista, sea la llamada vivienda de los Padres Paules, en la calle Villalba, 2-4; sobre un solar de $200 \mathrm{~m}^{2}$ se desarrolla un edificio de dos plantas que presenta una decorativa fachada que se corona con dos espadañas apuntadas. Frisos florales recorren su parte superior a modo de bandas. Lo ornamental aparece en enmarques de vanos, formas estrelladas de simbología oculta, antepechos de ventanas y molduras. Bajo los balcones se desarrollan motivos de reposadas ondulaciones vegetales. En la esquina campea un águila de alas abiertas, como único elemento zoomorfo. 
Existen pocos portales que pudiéramos considerar modernistas, debido a la escasez de edificios de varias plantas, y a que el tiempo posiblemente haya degradado algunos ejemplos, como es el caso de Castilla, 30, donde dos molduras de mujeres de medio busto sostienen un dintel, en mal estado de conservación a causa de los blanqueos. En Bilbao, 14-16, aparece totalmente estucado, con bandas florales en rosa, que crean un vistoso espacio.

Otras casas profusamente decoradas son las situadas a la derecha de la calle Mezquita, en Jiménez Iglesias, 48-50, que se asientan sobre una manzana de seis solares $\left(600 \mathrm{~m}^{2}\right)$ y que aparecen todas con la misma decoración, presentando pues un aspecto unitario y fachada a cuatro calles. Se constituye en ejemplo muy interesante y de gran empaque.

En Castilla, 11, tenemos un edificio de 3 plantas, caracterizado por una gran balconada clásica de corte historicista, a base de columnas y cristaleras. Los laterales están decorados con enmarques, unos geometrizantes, otros de trazado más sinuoso.

Varios tipos de ménsula realzan el conjunto que se desarrolla verticalmente, pues el solar de $100 \mathrm{~m}^{2}$ no da para más, al estar ceñido por otras edificaciones laterales.

El portal es de pequeñas proporciones. Formado por dos cuerpos: el primero tiene cerámica vidriada en sus bajos, y el techo con estucos y florón central del que pendería en su tiempo una lámpara.

El acceso al segundo cuerpo se hace mediante un arco floral, que precede a las escaleras de ondulante trazado.

Plenamente integrado en la reacción contra el modernismo aparece el edificio de la calle Vitoria, 18, de tres plantas, sobre solar de $200 \mathrm{~m}^{2}$. Representa ya el estilo novecentista de Enrique Nieto, así lo lineal y geométrico constituye el fundamento de su estructura. La decoración a base de esgrafiados en los enmarques de tonalidades verdes, y ménsulas de una plástica entre lo volumétrico y lo orgánico, se ha depurado de una serie de elementos modernistas.

Su portal es un buen ejemplo de un tipo muy difundido de estos en Melilla que responde a una estética Art Deco. El que nos ocupa aparece con estucados finos y relieves en el techo muy lineales, estilo que se expresa también en la puerta de acceso.

Otro paso evolutivo lo representa la tendencia racionalista, que se muestra aquí, de forma relativa, pues lo decorativo nunca abandonará estos edificios, construidos a partir de 1940, en forma de esgrafiados geometrizantes de corte novecentista.

Espacios salientes y intrantes son sus rasgos distintivos. Tal vez los más representativos sean los de Aragón, 22, Aragón, 21, este con decoración estilizada de palmas de tipo egipcio y ladrillo visto de tonalidades ocres, así como otros enclavados en la calle Mar Chica, 19, 25 y 41.

Buen ejemplo de la mixtificación lo teníamos en Andalucía, 32, garaje de planta baja $\left(100 \mathrm{~m}^{2}\right)$, que representaba una fachada totalmente lisa, con una limpieza ornamental absoluta. 
Un sencillo juego de volumen combinaba el espacio de interesante modo. Coronando, una movida balaustrada modernista a base de circulos vegetales profudamente decorados, que hacía de este edificio una extraña y confusa solución entre lo lineal y lo ondulante.

Hoy dia, como en otros muchos casos, la balaustrada se tiró, y no es posible apreciar su verdadera dimensión.

Junto a estos edificios, con unas caracteristicas singulares o destacables, existe un elevado número de ellos con elementos ornamentales y decorativos que adquieren su verdadera significación precisamente por dotar a todo el barrio de una impronta particular, de un lenguaje que podemos observar por un lado o por otro.

El número total de casas con estas caracteristicas es de 147, lo que constituye alrededor de un $18 \%$ del total edificado.

Dentro de estos elementos ornamentales señalaremos como muy características los antepechos de ventanas, las representaciones antropomorfas y los enmarques de vanos.

Del primero existen unos cinco tipos básicos, todos ellos expresan la ondulación de la hoja como fundamento de su estructura. Se apoya también en el calado para resaltar en volumen estas líneas curvas, hojas que se disponen en círculos, exponentes del "coup de fouet" modernista.

Aparece en pocas casas, pero su número debió de ser muy superior.

Los elementos zoomorfos no destacan por su número, que es muy escaso.

En casi todos los ejemplos, se muestran leones, excepto el del águila citado; estos se desarrollan en las cornisas, con rostro de pequeño tamaño y actitud fiera, sus rasgos son toscos, como el ejemplo de Aragón, 13.

Otros, más serenos y de mayor tamaño, también en relieve de cuya boca salen guirnaldas de flores y hojas (rosas y margaritas), en Mallorca, 3 o en Jiménez Iglesias, $40-42$.

A medio camino de lo vegetal y lo humano se encuentra el mascarón que representa la cara de un genio, en los soportes de balaustrada de Jiménez Iglesias, 40-42.

Hay que citar como muy interesante, en otro terreno, la cornucopia con fecha en su óvalo central, que hay en Lugo, 49 . Si la fecha que en esta figura es cierta, 1910, esto podría demostrar una muy temprana formación y trabajo de las escuelas de yeseros en este barrio, en el mismo año que empieza a construirse.

Es el único elemento decorativo que queda de esta casa, y amenaza con caerse siendo muy deseable su recuperación, pues podría ser la moldura más antigua de todo el Real.

Pasemos finalmente a ver los enmarques que se sitúan en los vanos de puertas y ventanas (34).

La clasificación que aquí presento, solo intenta ser un modo más o menos correcto de acercamiento a la riqueza decorativa, que en su raiz es incatalogable,

(34) Ver la clasificación en los anexos 1 y 2. Mi agradecimiento a Lucas Calderón Ruiz por su ayuda a elaborar la clarificación. 
para desmenuzarla en sus últimos elementos. De esta forma puede estudiarse como se van conformando los conjuntos, artesanalmente, combinando hasta la saciedad múltiples molduras en diversas fachadas.

Estos enmarques, en mi opinión, pueden ser los elementos más caracteristicos de cientos de fachadas en la ciudad, tal vez no los más importantes, ni destacados u originales, pero sí los más extendidos y donde se puede seguir fielmente una evolución estética a la vez que configuran toda una serie de edificios.

Ya se ha citado y hay que repetir, que este bajar al detalle, a la moldura no debe hacer perder la imagen del Real, y éste junto a otros barrios, de Melilla, como un todo, como un conjunto orgánico que se expresa en un lenguaje, y este lenguaje es el modernismo.

Existe un total de 639 enmarques que obedecen a 38 tipos diferentes. En estos, distingo tres corrientes: una antropomorfa, otra de tipo geometrizante, y una tercera donde las ondulaciones vegetales irrumpen con fuerza.

En cuanto al elemento humano sólo hay tres tipos, que aparecen en siete casas con un total de 32 enmarques.

Uno de ellos, cara A, de rasgos orientales y de gran belleza femenina, está rodeado de molduras estilizadas.

El tipo B, muestra una más ondulante y sinuosa decoración, donde los tallos se retuercen en curvas de suave trazado, ciñendo un rostro femenino clásico con casco que nos llevan a las tocas del renacimiento italiano, Cataluña, 52.

Por último el único ejemplo masculino, se encuentra en Castilla, 30, de actitud seria y toca de compleja composición orientalizante.

Dentro de los geométricos tenemos once tipos con tres variaciones, hay un total de 206 enmarques en 39 casas.

Podemos ver algunos absolutamente lineales, inscritos en la estética Art Deco, como el tipo F. Otros combinan figuras geométricas, como el A y sus variantes.

En los demás casos, hace aparición lo vegetal, pero la estructura predomina sobre este elemento, las líneas no llegan a ser desbordadas por las curvas como en los tipos B, D, E, E', G, G', H, N, Ñ.

En aquellos que las ondulaciones vegetales son el elemento caracterizador es donde el modernismo se muestra en su mayor pureza. Presenta un total de 16 tipos con cinco variantes. El número de enmarques es de 386 en 54 casas.

$\mathrm{La}$ diversidad como vemos es mayor.

Hay algunos que se desarrollan sobre un motivo central y dos florones laterales, en combinaciones diversas de flores, hojas, guirnaldas, tallos, como en los tipos $7,7 ", 8,8$, 8", o el 13, este último de gran rudeza.

En otros, largos tallos ondulados se esparcen por toda la moldura con gran profusión, Tipos 2, 2', 10, 18, 19 y 21.

Tipo más interesante es cuando lo sinuose conforma el mismo marco, escapando de las líneas geométricas que lo ciñen, asi los tipos $1,1,3,9,11$, 12,20 y 30 .

El tipo 14, nos recuerda la caligrafía árabe en otra directa alusión a lo oriental. 
Estos elementos por regla general no se reducen como puede suponerse a un solo barrio, o edificio (aunque existan algunos que solo han sido utilizados en una ocasión) sino que forman parte de un lenguaje común a toda la ciudad, que a su vez es consecuencia de la creatividad del arquitecto Enrique Nieto.

Vemos así, como el barrio del Real se inserta en la ciudad modernista de Melilla, no por los edificios singulares, sino por la abundancia decorativa de sus fachadas, que en la mayoria de los casos es lo único que hoy nos queda de un movimiento cultural de amplio espectro que se extendia a diferentes artes y aspectos de la vida cotidiana.

Por último señalaremos que ninguno de los grandes edificios públicos del Real están construidos, sorprendentemente, en estilo modernista, hecho que se repite en toda la ciudad.

La Iglesia del San Agustin, es de tipo funcional bastante simple.

De los cinematógrafos, el Real Cinema carece de cualquier interés artístico. El cine Español (cerrado) es el único que posee una fachada decorada con varias molduras de tipo vegetal, siendo sus proporciones pequeñas.

El matadero público no tiene especial interés decorativo, y el Mercado del Real, presenta un ecléctico estilo entre el funcionalismo y un original revival historicista, siendo una edificación, de gran envergadura. 


\section{ANEXO 1. ${ }^{\circ}$}

Cuadro con tipos y número de enmarques y edificios donde estos se dan (35)

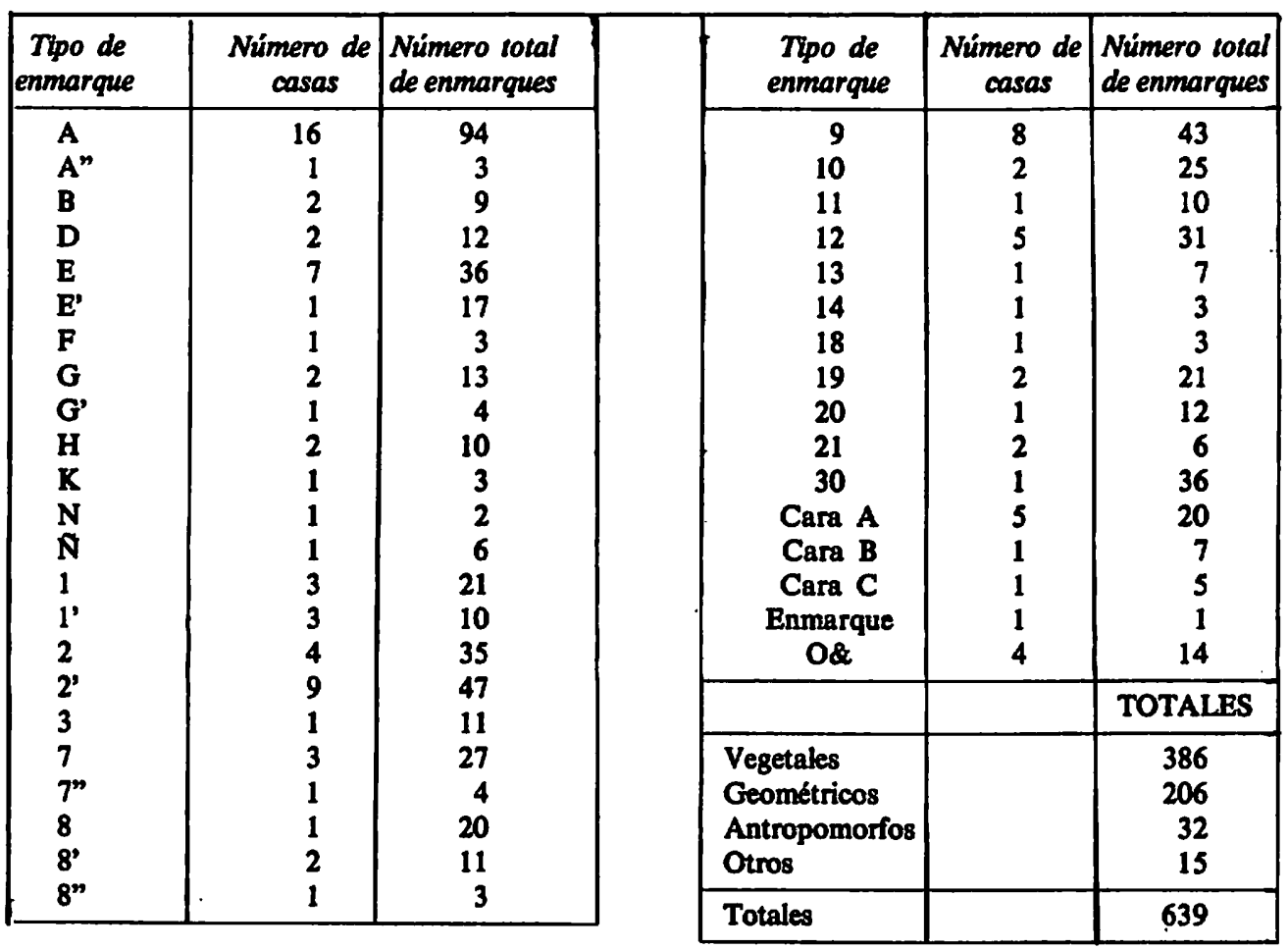

(35) Nota a los anexos 1 y 2.

Esta clasificación es parte de otra mayor, que comprenderá toda la ciudad, por lo que a veces hay saltos en el orden de las letras o los números que designan tipos de marcos, cuando haya alguno de estos que no esté representado en el Barrio del Real. 
ENMARQUES GEOMETRICOS

\section{ENMARQUES ANTROPOMORFOS}
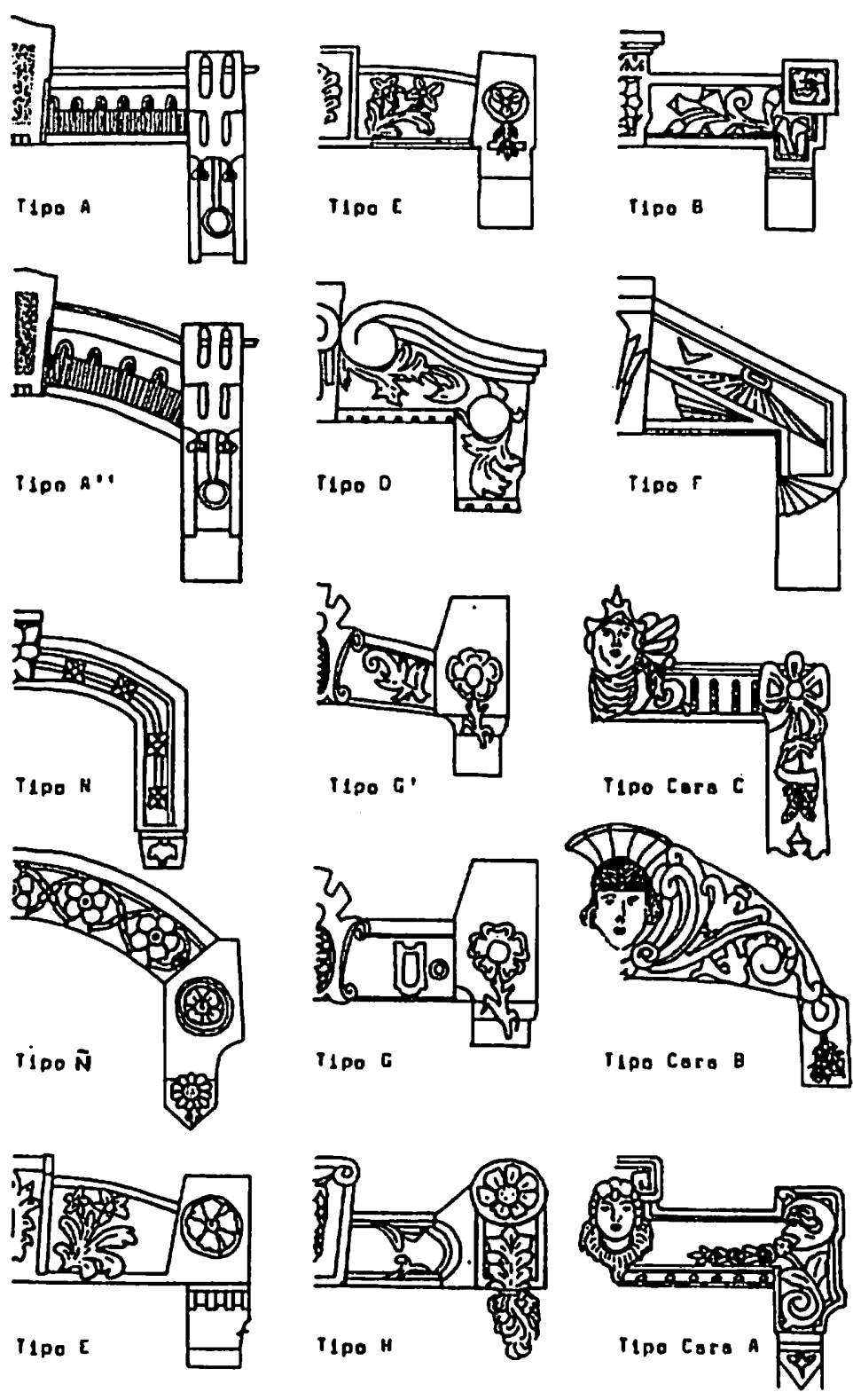


\section{ANEXO II}

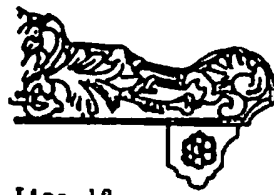

I 1 po 18
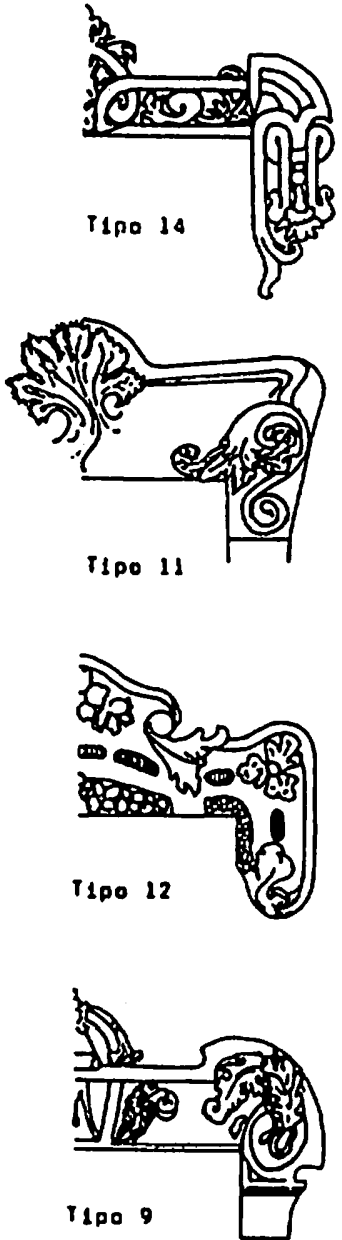

\section{ENMARQUES VEGETALES}
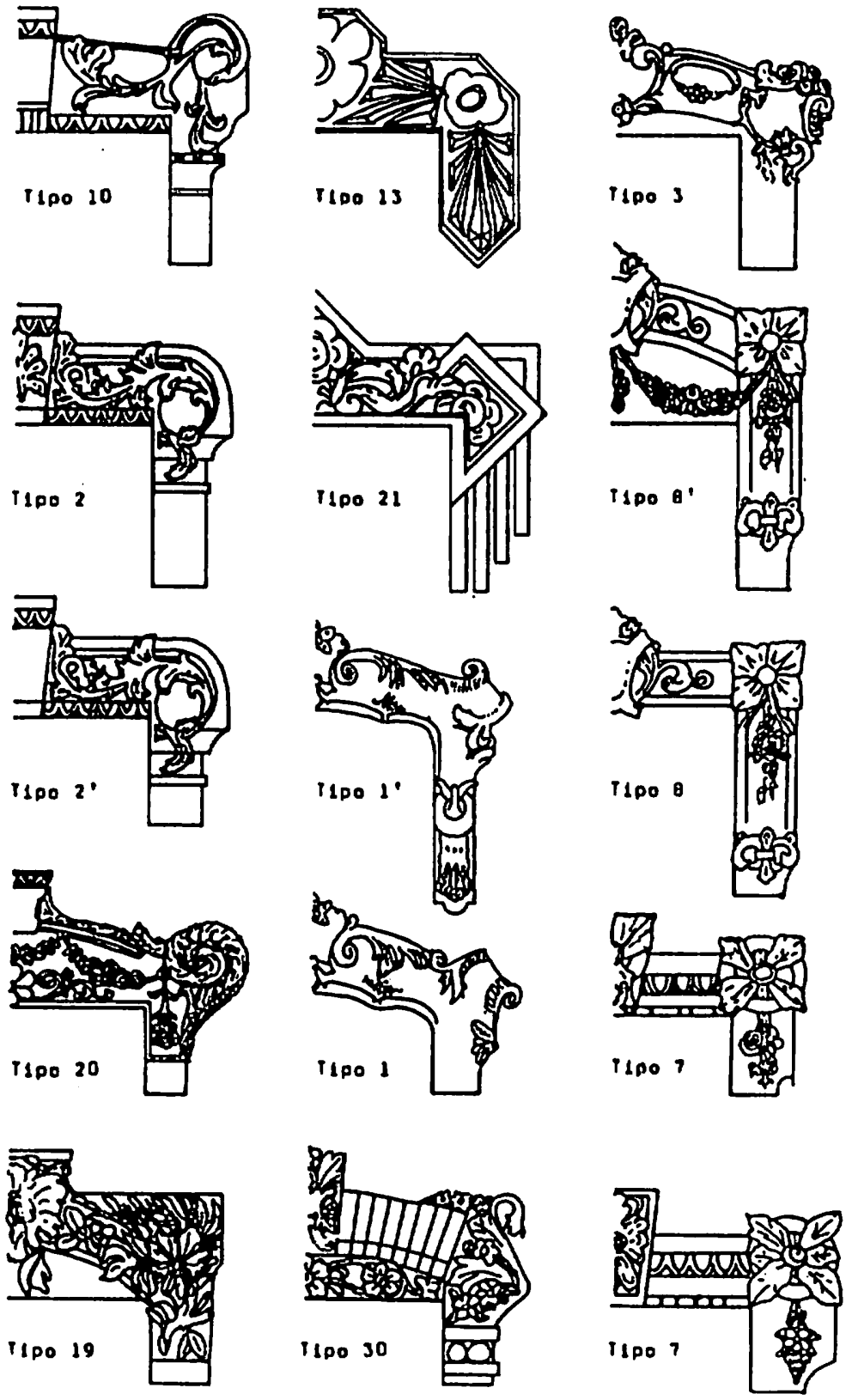